\title{
ESPAÇO E SUBJETIVIDADE: FORMAÇÃO E INTERVENÇÃO EM PSICOLOGIA COMUNITÁRIA
}

\author{
Conrado Ramos \\ João Eduardo Coin de Carvalho \\ Universidade Paulista, São Paulo, Brasil
}

\begin{abstract}
RESUMO: As práticas em Psicologia Social Comunitária (PSC) estão diretamente relacionadas ao compromisso com a mobilização de populações excluídas e com desafios à identidade profissional do psicólogo. Neste trabalho apresentamos uma experiência de intervenção e formação em PSC no curso de Psicologia da Universidade Paulista. Foi realizada pesquisa etnográfica junto ao Complexo da Funerária, conjunto de favelas da Zona Norte de São Paulo, e entrevistadas seis lideranças sobre a história da comunidade. Todo material foi submetido à análise de conteúdo. Os resultados mostram a importância das dimensões psico-espaciais para o reconhecimento da comunidade, materializadas na imbricação das características físicas do espaço e da história das lideranças. Concluímos pela potencialidade da associação entre intervenções que permitam trabalhos de extensão com atividades de pesquisa e formação, uma estratégia importante no redirecionamento crítico e engajado do profissional para dimensões comunitárias, institucionais e sociais do saber e do fazer da Psicologia brasileira.
\end{abstract}

PALAVRAS-CHAVE: Psicologia Social Comunitária; favela; comunidade; formação em Psicologia.

\author{
SPACE AND SUBJECTIVITY: PROFESSIONALEDUCATION \\ AND SOCIAL INTERVENTION IN COMMUNITY PSYCHOLOGY
}

\begin{abstract}
Community Social Psychology helps people to understand and modify their social realities. This work, that compromises those individuals and also the psychologist, is many times a challenge to his/her professional identity. The aim of this research is to discuss a particular experience on the association of professional and academic formation in Community Social Psychology inside a private university in Brazil. During a year we conducted an ethnographic research among people from some shantytowns situated in São Paulo and six community leaders were asked about shantytowns histories. The results show how the relationship between leaders psychosocial characteristics and neighborhood spatial features are important to understand community dimensions. Community Social Psychology interventions associated with research and university academic formation have a decisive role within the constitution of a critical professional identity, keeping psychologists as important actors in Brazilian social context.
\end{abstract}

KEYWORDS: Community Social Psychology; shantytown; community; higher education in Psychology.

\section{Psicologia Social Comunitária}

Surgida após a crise da Psicologia Social em meados dos anos 1970, a Psicologia Social Comunitária, especialmente na América Latina, se apresentou como uma abordagem diferenciada para a inserção profissional e política do psicólogo. Andery (1986), em trabalho que procedia a uma avaliação do movimento no Brasil, já indicava a vocação da Psicologia Comunitária para o compromisso com as classes populares, desafiando os modelos de ação psicológica de atendimento à elite e a serviço do controle social, colocando por chão a possibilidade de uma prática profissional e científica fundada na neutralidade. Neste sentido, as ações de pesquisa e intervenção nesta abordagem tenderam a privilegiar metodologias qualitativas, nas quais se aliava a preocupação transformadora tão cara à Psicologia Comunitária, preservando seu caráter investigativo e de produção de conhecimento (Lane \& Sawaia, 1995).

Os resultados destas práticas vieram se mostrando efetivos, enquanto críticos do status quo e mobilizadores das populações mais pobres para a mudança de suas realidades, na medida direta da participação destas populações em todo o processo de investigação e transformação: do diagnóstico à intervenção, passando pelo estabelecimento de objetivos comuns. Isto, no entanto, vem solicitando uma mudança importante também na disposição do próprio profissional, aberto para uma ação que seja de composição e compartilhamento de responsabilidades, levando a incertezas e desafiando a identidade profissional (Freitas, 1998). 
A formação de profissionais sensíveis a uma prática psicológica conseqüente e comprometida com a crítica aos processos de exclusão social exige uma preparação que, atravessando todo o curso, põe em jogo aspectos científicos, metodológicos e ainda éticos. Colocados em contato direto com demandas estranhas àquelas de uma clínica particular e isolada das questões sociais, alunos e professores enfrentam a diferença, a incerteza e, ainda assim, vêm descobrir as potencialidades profissionais e sociais ligadas a estas ações de investigação e transformação (Ramos \& Carvalho, 2006). Para isto, se deslocam física e simbolicamente para áreas de exclusão nas quais podem ser identificados três campos de batalha onde estas ações se darão, onde há submissão e resistência: o corpo, sujeito ao controle e ao sofrimento, mas sede da subjetividade e local de onde o indivíduo realiza as experiências de sua inserção no mundo: é o corpo que circula pelo espaço vivido; o cenário social (e grupal) de pobreza e isolamento, os marcos históricos do grupo, seus movimentos no tempo e no espaço; e o espaço físico, construído de forma orgânica, muito mais do modo como é cotidianamente vivido do que por uma lógica que lhe é externa, espaço onde os campos de batalha se materializam.

\section{Pobreza e Espaço}

As práticas em Psicologia Comunitária se dão no contexto de um país que ainda ocupa no mundo um dos piores lugares no ranking da desigualdade de renda (Ferreira, Leite, \& Litchfield, 2006). Esta circunstância revela um contexto explosivo onde coexistem riqueza e extrema pobreza, com as favelas das grandes cidades localizadas lado a lado com as vizinhanças mais ricas. Como consequiência de ao menos um século de negligência do Estado, com o beneplácito da elite política e econômica, a urbanização desordenada associada com a falta de uma política habitacional adequada pôs milhões de pessoas vivendo em locais fora do alcance dos serviços públicos (coleta de lixo, educação, saúde), sujeitos à presença hoje opressiva de traficantes (Valladares, 2000).

Furtado (2003) aponta a questão habitacional como central para compreender a pobreza estrutural - e então a exclusão - entendida como um obstáculo permanente para incrementar a economia das populações mais pobres, que gastam uma parte significativa de seus salários com aluguel - mesmo nas favelas. Na cidade de São Paulo esta precariedade habitacional se iniciou na década de 1940 , quando espaços vazios da cidade foram ocupados a partir de uma crise de habitação (Novara, 2003a). Estes espaços têm crescido desde então. Até recentemente, como efeito da crise econômica e do desemprego, a população que vive nas favelas em São Paulo cresceu proporcionalmente mais do que a população da cidade. Enquanto a população total aumentou 8\% de 1991 a 2000, o número dos habitan- tes nas favelas aumentou $41 \%$, alcançando mais de $1 \mathrm{mi}-$ lhão de pessoas (Sampaio \& Pereira, 2003). Além disso, tanto o governo federal quanto os governos locais têm sido incapazes de contribuir para a cidadania e o reconhecimento social efetivo destas populações. Embora os moradores das favelas tenham uma presença espacial e humana expressiva, a sociedade e o governo não os reconhecem como habitantes da cidade, o que os mantém invisíveis, vivendo muitas vezes sem o necessário suporte público imprescindível para educação, saúde e trabalho.

Compreender este cenário para cada comunidade específica tem sido condição para a implantação de ações transformadoras junto a populações que vivem nessa situação (Novara, 2003b; Ohtake, 2006), um processo de conhecimento que se pauta ainda pelo desafio metodológico (Spink, 2007). Mais ainda, a "chave" para a leitura cultural de uma favela pode ser encontrada na sua própria e complexa lógica espacial: uma lógica muito mais orgânica e vital do que ordenada e racional (Jacques, 2002). Uma lógica labiríntica (como a vida dos moradores das favelas) e não moderna, projetada e progressiva (como pretende ser a vida dos moradores dos bairros formais). É nesta perspectiva que podem ser compreendidas também as relações com o tempo, isto é, com a história de uma comunidade.

\section{O Complexo da Funerária}

Dentro deste contexto, professores e alunos da disciplina de Psicologia Social do Curso de Psicologia do Instituto de Ciências Humanas da Universidade Paulista (UNIP) vêm realizando desde 2003 um trabalho de investigação e intervenção junto ao Complexo da Funerária, um conjunto de comunidades da Zona Norte da capital de São Paulo. As comunidades em questão são Vila Nova Tietê, Vila São João, Cidade Nova, Funerária e Nova Curuça. Todas estão localizadas no entorno de um grande terreno do Serviço Funerário da Prefeitura de São Paulo. O trabalho se iniciou após longo contato entre as lideranças comunitárias, representantes da Polícia Militar do Estado de São Paulo (PMSP) e representantes da UNIP. $\mathrm{O}$ projeto comum, inicialmente proposto pela PMSP que apoiou nossos trabalhos e visitas em um primeiro momento - consistia no resgate à cidadania da população excluída destas comunidades.

\section{Objetivos}

Como parte do trabalho de aproximação das comunidades, nosso objetivo foi o de estabelecer um reconhecimento do espaço e dos sujeitos das vilas, escutando e registrando as demandas desta população. Esta ação se justificava pelo compromisso com a organização de pro- 
jetos de pesquisa e de intervenção psicossocial associados às disciplinas de Psicologia Social e a estágios e cursos de Extensão na área de Psicologia Social Comunitária, oferecendo, de um lado, os recursos da Universidade para ações continuadas e compromissadas com os interesses da comunidade, e, de outro, aos alunos, o contato teórico e prático com ações que caracterizam o universo de atuação profissional do psicólogo, dentro de uma perspectiva política e crítica.

\section{Método}

Nosso projeto consistiu em encontrar o fio de Ariadne que pudesse desvendar ou construir um percurso histórico coletivo, que apresentasse, projetivamente e em movimento, a identidade social das comunidades estudadas. Não se tratava de dar uma ordem racional ao que tem uma vitalidade orgânica, pois isto seria negar a identidade em questão. Não seria um projeto de linearidade histórica, de datação de fatos. Mas da orientação de uma narrativa compartilhada, da costura de marcas coletivas comuns, para que não se perdesse e para que mostrasse, em suas relações, um desenho comum da história da exclusão e dos excluídos do lugar. Uma colcha de retalhos que servisse como fonte imagética para o auto-reconhecimento e para a organização dos grupos, pelos próprios grupos. Por isso, foi importante que esta história não fosse construída a partir de documentos, mas das memórias. Os documentos poderiam servir para ilustrar as recordações. Mas só uma história afetiva deveria servir à construção de uma identidade grupal.

Ao longo de um ano foi realizada uma investigação etnográfica, conduzida por professores e alunos de $3^{\circ}$ e $4^{\circ}$ semestres do Curso de Psicologia, através de visitas às comunidades, participação em ações sociais encabeçadas pelas Polícia Civil e Militar do Estado de São Paulo (fornecimento de documentos de identidade) e pela Universidade (cursos de extensão para os moradores), participação em festas, eventos esportivos, de lazer e religiosos, acompanhadas de moradores e de lideranças. Seis líderes, um da Vila Nova Tietê (J.), dois da Vila São João (M. e V.) e três da Cidade Nova (A., G. e J.) foram ainda entrevistados sobre a história da comunidade. Importante esclarecer que $\mathrm{V}$. foi a única liderança do sexo feminino que encontramos e que à exceção de V. e G., os demais são moradores das vilas mencionadas (V. nunca morou dentro do Complexo da Funerária, mas lá trabalha todos os dias, e G. já foi morador, tendo parte de sua família residindo na Cidade Nova). Além disso, excetuando A. que tinha menos de 30 anos, os demais líderes possuem mais de 50 anos. Todo material, registrado e gravado, foi submetido à Análise de Conteúdo (Bardin, 1976).

Desde que, toda a etnografia (observação e entrevistas) não compunha propriamente a investigação de um problema, senão a aproximação e compreensão das co- munidades em questão, foi somente aos poucos, com discussões, reflexões e a escuta das entrevistas que as categorias de análise foram emergindo. As observações e as entrevistas tinham, pois, inicialmente, objetivos bastante "inespecíficos", como sociabilidade, história e espaço. Por isso, o conjunto dos resultados apresentados a seguir deve ser compreendido também na forma de um "passeio" pelos espaços não sistematizados das próprias comunidades visitadas. O método adotado, pois, se assemelha e se confunde com seu objeto, mas talvez como única forma de dele extrair a riqueza de sua face não sistematizada. É importante que não se confunda, no entanto, fluidez e adaptação do trato metodológico com falta de rigor.

\section{Resultados e Discussão}

\section{O Cenário e os Atores}

As primeiras análises desta investigação sobre a comunidade mostram que a idéia de um projeto efetivamente "comunitário" (Guareschi, 1999), coletivo, parece comprometida. A preocupação com a solução de problemas imediatos não deixa entrever um tempo no qual a vida será melhor, quando a favela deixará de ser favela e passará a ser um bairro, quando a violência não será endógena, quando haverá trabalho e sucesso. Mesmo que isto remeta a circunstâncias bastante diversas daquilo que acontece com as classes mais favorecidas, em relação a um caminho natural de desenvolvimento e de sucesso, esta disposição dos moradores da comunidade se mostra muito semelhante a de outras classes se evocamos o eixo deste "progresso". Guardadas as devidas proporções, na batalha pela sobrevivência cotidiana aqui também sobressai a preocupação com possuir determinados bens - uma geladeira, um forno de microondas, uma televisão, um automóvel - como sinal de existência social. A possibilidade de ser atendido por uma loja de departamentos, de poder ser reconhecido como consumidor em um supermercado, é apresentada como sinal desta passagem para uma vida melhor, nos limites daquilo que se pode aspirar como "sucesso".

A fantasia da promiscuidade ou das relações "comunitárias" se esvai. As casas - que os moradores fazem questão de diferenciar dos barracos que ainda existem em certas áreas da comunidade - foram construídas a partir da ocupação de pequenos terrenos com a dimensão de um cômodo, originalmente colados uns nos outros, apertados por muros e passagens para áreas internas onde só pode passar um morador de cada vez. Portas que se abrem para janelas dos vizinhos mas que são impermeáveis à constituição de interesses comuns e através das quais pode-se ver crianças vendo televisão ou jogando videogame, trancadas por mães que temem o que pode acontecer com seus filhos nas vielas escondi- 
das e "preservadas" para a violência e para a ação do tráfico.

Mesmo assim, todos afirmam como cada comunidade está melhor, como hoje podem circular entre elas sem medo de serem reconhecidos como estrangeiros e inimigos. Ainda neste caso, a violência é como uma sombra que às vezes preocupa, outras explode. A história das comunidades está marcada pela sua presença, antes, de fora para dentro - o grileiro, o supermercado que também invade um terreno público. Depois, entre as comunidades. Agora, dentro de cada comunidade, entre os diversos grupos que convivem ali. A superação dos problemas mais imediatos - água, luz, esgoto, inundações - vai oferecendo espaço para a instalação de novos problemas: a violência, a criminalidade, o tráfico, a gravidez precoce, o que pode ser sintetizado com a preocupação de J. quando pergunta "O que vai ser de nossos filhos? O que podemos fazer para evitar o pior?”.

O contato com os homens da comunidade - são eles que se apresentam para as nossas ações - revela sua diferença de posição em relação aos jovens e às mulheres. Atender aos jovens não se apresenta como prioridade. Suas demandas não têm acolhida, parecem não fazer sentido: lazer, futebol, dança, são pedidos frívolos para quem já colocou a própria vida em risco por causa de $20 \mathrm{~m}^{2}$ de terreno ou pelo uso de uma lâmpada. A atuação das mulheres na comunidade neste momento é uma incógnita e chama a atenção a ausência de mulheres como lideranças (com exceção de V., que no entanto, não é e nunca foi moradora do local). Antes, segundo pôde-se escutar, elas estavam presentes na ocupação dos terrenos e na instalação das vilas, cuidando da casa e do espaço, ao mesmo tempo em que eram respeitadas como porta-vozes das reivindicações da comunidade. Agora, dão espaço para os homens, os principais interlocutores no contato com o "mundo exterior", constituindo ao que parece a favela como um espaço eminentemente masculino e reforçando o ideal social do homem ocupando o espaço público, enquanto "o lugar da mulher é em casa" (Finamore \& Carvalho, 2006).

\section{O Labirinto}

As entrevistas sobre a história (ou histórias) da comunidade realizadas com as lideranças, quase sempre homens, localizam uma série de elementos que auxiliam na solução deste quebra-cabeças. Inicialmente localizamos três eixos históricos presentes nas falas dos líderes: a história pessoal, a história da comunidade e a história de outras lideranças. A história pessoal é pontuada por marcos afetivos, mais do que por mudanças de grupos ou por posições sociais:

"O dia em que alcancei a graça de Santa Teresinha...” (M.).
"O dia em que fiz a mulher de quem levaram o filho ter esperanças...” (J.).

"O dia em que vi meu padrasto bater em minha mãe...” (A.).

"O dia em que me deram tiros, mas não me acertaram...”(J.).

Há também os marcos históricos coletivos. Estes são dados por derrotas e conquistas da comunidade, como a chegada dos ônibus de transporte público, a invasão coletiva de uma área cercada, a festa de São João que deu origem ao nome de uma das vilas, a construção da primeira escola dentro da comunidade, o mutirão para organizar as ruas, um dos muitos incêndios que assolou a comunidade, ou ainda a ação de tratores que vieram derrubar barracos já construídos e ocupados.

No cruzamento das histórias pessoais (isto é, do corpo, enquanto sede da subjetividade que transita pelo espaço vivido) com a história coletiva (ou seja, o cenário social), o que vemos é uma história de luta cotidiana, mas dispersa, muitas vezes sem a preocupação com a organização temporal em seus discursos. Essa história de luta cotidiana se materializa na mesma forma do espaço físico. As falas vão e vêm no tempo, "passeiam" nele sem uma preocupação com a linearidade ou com a costura de um enredo único; compõem-se de um mosaico de evocações significativas que, embora fragmentadas, permitem, a certa distância, a composição de uma história local. É uma história dos momentos que fortalecem os vínculos e a disposição de luta, não uma história em blocos, periódica ou progressiva. Não é uma história do progresso, apesar das conquistas reconhecidas, é uma história de heroísmos anônimos, de tentativas de ser, pessoal e coletivamente, mais do que de crescer. Uma história de exclusão e de excluídos. Nela, as marcas coletivas e pessoais não reforçam objetivos e projetos claros de passado e de futuro; parecem servir para desenhar os percursos da sobrevivência cotidiana: são pontos de emersão singular ou coletiva, pontos ou marcos identitários de um vir-a-ser cotidiano sem contornos claros, porque muitas vezes negado ou interrompido. A história é um aglomerado de dias vividos que ganham sentido em memórias afetivas e compartilhadas; ela não é um constante preparo, uma "carreira", um "empreendimento". Ela também não é naturalizada: nascer, crescer, casar, ter filhos... É imprevisível e insegura: escapar da morte, dar conta de um problema imediato, tentar, frustrar, não desistir. Dificilmente dois entrevistados se remetem aos mesmos fatos passados. Cada um traça a sua história que é, no entanto, desenhada como a história de todos. A história da comunidade, pelos líderes, não é uma repetição formalizada de fatos e etapas, com sentidos únicos e decisivos; é um quebra-cabeça emocional, uma história múltipla e coletiva, com desvios, becos sem saída e 
passagens estreitas, não com quarteirões retangulares padronizados. O discurso é organizado pelas necessidades tanto quanto o próprio espaço. É uma organização vital espaço-temporal. A percepção da história acompanha a do espaço e vice-versa: é muito fácil e perigoso se perder nos caminhos da favela. A paisagem muda a cada 15 dias (intervalo comum entre nossas visitas). Não há referências claras, precisas e seguras, tanto para a orientação espacial quanto para a temporal. A necessidade de compreensão geralmente manifestada pelo visitante da favela pede pela visão aérea do espaço total (num vôo de Ícaro). Aqui, ao falarmos de história, carecemos de uma visão cinética, da origem ao presente (um olhar de Cronos).

Há ainda um terceiro eixo: aquele da história dos próprios líderes, os antigos e os atuais. As brigas e os conflitos internos, as políticas de lideranças, são comuns e seguem o mesmo percurso labiríntico: líderes que somem, outros expulsos, os que se apossam, os que se acomodam e os que desistem, os legítimos e os oportunistas, os modernos e os tradicionais, os que se impõem pela força, os organizados e os paternalistas, os heróicos. São diversas formas de lideranças porque são múltiplas as relações co-existentes: relações políticas, criminosas, interesseiras, engajadas, assistencialistas, esclarecidas, passivas, ingênuas, desesperadas, todas em convivência, numa mesma região e numa mesma época. Teseus e Minotauros juntos num labirinto em que o construtor, Dédalo, são todos e é cada um.

As lideranças também se repõem cotidianamente. Sua legitimidade é difusa, sua representatividade é incerta. Este também é um lugar movediço, em transformação, assim como a paisagem, a arquitetura, a população. As lideranças são mais orgânicas do que organizadas: elas também atendem mais às necessidades imediatas de sobrevivência, que se lhes impõem pelas próprias condições de exclusão, do que a projetos racionalmente construídos. Por isso são diversas lideranças e de diversos tipos. Todas são possíveis na malha dispersa das relações cotidianas. Não há centralização, há dispersão - e às vezes fragmentação - assim como a própria estrutura da favela, que se espalha por avenidas, ruas, caminhos, vielas, trilhas e becos. Labirinto espacial, humano e de relações.

\section{Em Busca do Fio de Ariadne: O Espaço Vivido e o Discurso das Lideranças}

As três comunidades do Complexo da Funerária que pudemos conhecer são profundamente marcadas pela sua história com o território. É uma história ecológica, de conquista e de ocupação, de construção e de melhorias, mas sempre uma história da sobrevivência do grupo. As diferenças entre as lideranças das comunidades também parecem se dar em função deste "espaço vivido", geran- do diferentes discursos e representações sobre si mesmas, diferentes identidades.

O discurso organizado dos líderes da Cidade Nova se assemelha a sua organização espacial, que se apresenta no próprio nome: "vamos reconstruir uma cidade nova" (G.). Lá podemos observar a presença de praças, de ruas projetadas e organizadas, graças à intervenção de uma religiosa católica então moradora da comunidade e a um engenheiro contatado à época da reconstrução. Lá, também, o Núcleo Sócio Educativo, equipamento subsidiado pela Prefeitura de São Paulo para atender crianças de 6 a 14 anos nos períodos em que se encontram fora da Escola, fica aberto ao público, como espaço de lazer de todos. Na Cidade Nova, curiosamente, dois dos líderes entrevistados (A. e G.) escolheram para suas entrevistas locais altos, que permitem a visão do entorno da comunidade (em especial G., cuja casa tem uma varanda para uma das praças da comunidade). Coincidência ou não, esses locais sugerem uma visão superior, controladora e organizada do todo.

Na Vila Nova Tietê, o discurso predominante é da falta de espaço, principalmente para o lazer. $\mathrm{O}$ aconchego e a proximidade afetiva dos seus líderes também podem ser relacionados à experiência da necessária proximidade física decorrente do "pouco espaço" que insiste em aparecer nas suas falas. Nesta comunidade encontramos um carinho maior manifestado, principalmente, pelo toque, que não aparece da mesma forma nas outras duas comunidades. Na Vila Nova Tietê, os líderes insistem em fazer tours pelas ruas e becos da comunidade, o que não é difícil dado seu tamanho. Pelo caminho vão contando histórias sobre a ampliação/redução do espaço, em especial as brigas e conflitos com um grileiro que reclamou a posse da terra e pagou capangas para perseguir e ameaçar os líderes, ou com os proprietários de uma grande empresa supermercadista, eles também sem a posse regular do terreno que ocupam e disputam palmo a palmo com a comunidade, construindo muros que impediram o avanço dos assentamentos.

Na ocasião em que conhecemos o grupo de capoeira do local, as falas giraram em torno da falta de espaços para os treinos enquanto J. tentava de todas as maneiras justificar sua posição de limitador do uso da sede da Associação de Moradores pelo grupo, argumentando que o espaço precisaria ser dividido por todos. As críticas aos governos municipais anteriores se dão em torno da construção de um conjunto de prédios que lhes retirou um campo de futebol, única área de lazer que possuíam. Além disso, queixam-se que a Prefeitura teria colocado manilhas muito pequenas para a saída de esgoto deste conjunto, gerando problemas constantes de entupimento.

Nestas e em outras falas, o que parece se repetir é uma idéia de reduto (no sentido territorial e afetivo). Em 
todas as nossas visitas foi sempre marcado, de maneira consciente pelos líderes desta comunidade, que o que eles mais gostam de nosso contato é justamente a presença, a atenção.

Na Vila São João encontramos, por parte de seus dois líderes, uma mágoa com uma das irmãs da comunidade, pela "invasão" de um prédio que dizem lhes pertencer. $\mathrm{O}$ assistencialismo está presente nas falas e atitudes, em especial de V., que por mais de uma vez quis associar a nossa presença com a doação de alimentos para a distribuição pela Associação de Moradores (isto é, M.). A centralização e o controle exercidos por eles também estão presentes na preocupação em não mandar as pessoas de São João para atividades em equipamentos das outras duas comunidades: "para lá os meus não vão" (M.). O discurso do líder desta comunidade, quando se trata de política, é saudoso em relação à época do Prefeito Jânio Quadros: "Naquela época sim, a gente tinha as coisas. A democracia é uma coisa boa, mas enquanto a gente fica brigando para ver o que quer e para quem dar, todo mundo fica com pouquinho. Não adianta” (M.).

Nesta comunidade, ainda, sentimos dificuldades em conhecer outros líderes e outros lugares: lá, nossa presença se limita ao espaço da Associação de Moradores. A pedido nosso, conseguimos passear pela comunidade, muito extensa e muito pobre. O líder só nos apresentou às pessoas mais velhas, moradores mais antigos da região. Pelo caminho, ia nos dizendo os benefícios que conseguiu para alguns dos moradores e explicando os nomes das ruas que, em alguns casos, também foram dados ou sugeridos por ele.

Em resumo, podemos perceber três posturas diferentes nas lideranças de cada uma destas comunidades. Estas posturas parecem estar associadas a uma relação particular com o espaço, isto é, a um certo "espaço vivido", que marca também suas relações com seus liderados: na Cidade Nova, com suas lideranças organizadas, o espaço se apresenta também organizado/planejado; na Nova Tietê, as lideranças afetivas remetem a um espaço reduzido mas aconchegante (reduto); já na São João prevalece o assistencialismo, e há uma clara centralização espacial.

\section{Conclusões: Pensando Intervenções Enquanto se Dá a Formação}

Os elementos analisados neste artigo revelam uma íntima relação entre o espaço físico vivido e o ser vivente, o corpo como tal e como lócus da subjetividade. Não cabe pensar essa relação em termos de causa e efeito, ou seja, por causa do espaço aconchegante as pessoas que ali vivem são, por efeito, afetuosas. A relação entre objetividade e subjetividade aqui considerada só ganha sentido por uma determinação dialética (caótica?) entre a cons- trução dos espaços e dos respectivos moradores/ freqüentadores. É a história de cada comunidade, portanto, que permite avançar no entendimento de suas dimensões objetivas e subjetivas e na inter-determinação de ambas.

No âmbito das práticas comunitárias, das intervenções e pesquisas em psicologia social comunitária, é importante destacar que o profissional e o pesquisador devem estar abertos à escuta de parâmetros que não coincidem com os modelos operacionalizados e sistematizados que acompanham a lógica administrativa e racionalizada do pensamento da classe social dominante. $\mathrm{O}$ puro e simples transporte de paradigmas de uma classe social a outra reflete muito mais a ação do preconceito cientificamente sustentado e a dominação ideológica presente em práticas bem intencionadas do que uma intervenção amparada em critérios éticos e políticos.

A investigação cuidadosa do cotidiano de uma comunidade e de seus determinantes históricos, materiais e psicossociais não pode ser compreendida no âmbito superficial da mera descrição. Não se trata de esclarecer a aparência da comunidade, mas de buscar na intrincada relação entre os fatores objetivos e subjetivos que orientam as ações do dia a dia de seus moradores/ frequientadores, a própria identidade do grupo. E essa identidade que emerge, tornando-se aparência depois de alcançada, é justamente aquilo que deve orientar as intervenções e pesquisas em uma comunidade.

Diante disso, a iniciativa de reconhecer a comunidade em várias de suas dimensões - aqui tratamos especialmente dos componentes sócio-espaciais - revelou-se uma estratégia acertada na preparação e execução de intervenções dirigidas às suas diferentes demandas de luta e organização. Nos últimos anos temos insistido em trabalhos na Vila Nova Tietê ("o reduto"), atuando preferencialmente junto a grupos de mulheres e a jovens envolvidos com atividades culturais e ações de promoção de saúde. Uma delas, diz respeito justamente à uma interferência no espaço, com o projeto de uma quadra esportiva, lugar de ampliação do lugar mas também de expansão de horizontes - para o lazer, o futuro e a permanência. De nossa parte, compreendemos estas ações como compartilhadas e já deixamos de ser reconhecidos como "benfeitores" - se chegamos a sê-los - para ocupar o lugar de parceiros comprometidos com a transformação da comunidade num projeto a médio e longo prazos.

Este trabalho não pode deixar de ser visto na perspectiva da formação de alunos de psicologia para a investigação e intervenção em comunidades. Quanto à formação, temos acompanhado o movimento de parte dos alunos que participaram destas primeiras iniciativas, retornado às mesmas comunidades, continuando suas ações através de estágios e trabalhos de extensão - muitas vezes voluntários e realizados agora por ex-alunos - 
que possibilitam propostas mais elaboradas de intervenção. Isto tem mostrado a importância, na trajetória de formação e construção da identidade profissional, da sensibilização com a realidade brasileira, da quebra de preconceitos sobre favelas e moradores de favelas e, principalmente, com uma visão mais responsável, crítica e engajada do papel social do psicólogo brasileiro.

Concluímos pela importância e potencialidade da associação entre intervenções que permitam o exercício do trabalho de extensão e compromisso social por parte das instituições de ensino superior com as atividades de pesquisa e formação. Neste caso, valoriza-se a realização de pesquisas e visitas técnicas, desde os primeiros semestres do curso, em campos de atuação da Psicologia marcados pelas demandas e condições da atual realidade brasileira, junto com a oferta de disciplinas de estágio nos últimos períodos do curso, voltadas para a atuação profissional. Tais iniciativas viriam retirar a Psicologia da tradicional repetição de seu enclausuramento em práticas individualistas e elitistas e em teorias calcadas na ideologia do capitalismo liberal. Esta pode ser uma estratégia de grande envergadura no redirecionamento crítico e engajado da Psicologia brasileira para dimensões coletivas, comunitárias, institucionais e sociais do saber e do fazer de nossa ciência.

\section{Referências}

Andery, A. A. (1986). Psicologia na comunidade. In S. T. M. Lane $\&$ W. Codo (Eds.), Psicologia Social: O homem em movimento (4. ed., pp. 203-220). São Paulo, SP: Brasiliense.

Bardin, L. (1976). Análise de conteúdo. Lisboa, Portugal: Edições 70.

Ferreira, F. H. G., Leite, P. G., \& Litchfield, J. A. (2006). The rise and fall of Brazilian inequality: 1981-2004 (World Bank Policy Research Working Paper No. 3867). Washington, DC: World Bank Policy.

Finamore, C. M., \& Carvalho, J. E. C. (2006). Mulheres candidatas: Relações entre gênero, mídia e discurso. Revista Estudos Feministas, 14(2), 347-362.

Freitas, M. F. Q. (1998). Inserção na comunidade e análise de necessidades: Reflexões sobre a prática do psicólogo. Psicologia Reflexão e Crítica, 11(1), 175-189.

Furtado, C. (2003). A habitação. Estudos avançados, 17(48), 184.

Guareschi, P. (1999). Relações comunitárias - Relações de dominação. In M. H. F. Campos (Eds.), Psicologia Social Comunitária: Da solidariedade à autonomia (3. ed., pp. 81-99). Petrópolis, RJ: Vozes.

Jacques, P. B. (2002). Cartografias da maré. In D. Varella, I. Bertazzo \& P. B. Jacques (Eds.), Maré: Vida na favela (pp. 13-65). Rio de Janeiro, RJ: Casa da Palavra.

Lane, S. T. M., \& Sawaia, B. B. (1995). La Psicologia Social Comunitaria en Brasil. In E. Wiesenfeld \& E. Sanchez (Eds.), Psicologia Social Comunitaria: contribuciones latinoamericanas (pp. 69-115). Caracas, Venezuela: Tropykos.

Novara, E. (2003a). Promover os talentos para reduzir a pobreza. Estudos Avançados, 17(48), 101-23.

Novara, E. (2003b). A favela como patrimônio da comunidade. Estudos Avançados, 17(48), 124-129.
Ohtake, R. (2006). Heliópolis: Um projeto de identidade cultural em conjunto com a comunidade. São Paulo, SP: Autor.

Ramos, C., \& Carvalho, J. E. C. (2006). Uma proposta de trabalho com grupos e instituições. In C. Ramos, G. G. Silva \& S. Souza (pp. 450-460). Práticas psicológicas em instituições: Uma reflexão sobre os serviços-escola. São Paulo, SP: Vetor.

Sampaio, M. R. A., \& Pereira, P. C. X (2003). Habitação em São Paulo. Estudos Avançados, 17(48), 167-83.

Spink, M. J. P. (2007). Pesquisando no cotidiano: Recuperando memórias de pesquisa em Psicologia Social. Psicologia \& Sociedade, 19(1), 7-14.

Valladares, L. (2000). A gênese da favela carioca: A produção anterior às ciências sociais Revista Brasileira de Ciências Sociais, 15(44), 5-34.

Conrado Ramos possui graduação em Psicologia pela Universidade de São Paulo (USP), mestrado e doutorado em Psicologia (Psicologia Escolar e do Desenvolvimento Humano) pela mesma universidade e é pós-doutorando do Núcleo de Pesquisa Psicanálise e Sociedade do Programa de Estudos Pós-Graduados em Psicologia Social da Pontifícia Universidade Católica de São Paulo (PUCSP). Atualmente é professor titular da Universidade Paulista (UNIP). conradoramos br@yahoo.com.br

João Eduardo Coin de Carvalho possui graduação em Psicologia pela USP, mestrado e doutorado em Psicologia (Psicologia Experimental) pela mesma universidade e pós-doutorado em Antropologia pela Johns Hopkins University, em Baltimore, EUA. Atualmente é professor titular do Instituto de Ciências Humanas e pesquisador da Vice-Reitoria de Pesquisa e Pós-Graduação da UNIP. Atua como professor colaborador da UNIFESP junto ao Núcleo de Estudos do Conhecimento (Depto de Neurologia) e ao Programa de Pós-Graduação em Medicina Interna e Terapêutica (Depto de Medicina). Endereço para correspondência: Universidade Paulista, Instituto de Ciências Humanas, Psicologia, Av. Alphaville, 3500, Santana de Parnaíba, SP, 14024-270. joaocoin@unip.br

Espaço e Subjetividade:

Formação e Intervenção em Psicologia Comunitária

Conrado Ramos e João Eduardo Coin de Carvalho

Recebido: 09/10/2007

$1^{a}$ revisão: 09/03/2008

Aceite final: 22/04/2008 